\title{
An Empirical Analysis of the Impact on Carbon Emissions of China's Urbanization
}

\author{
Hongjuan Zhang ${ }^{1,2, a}$ and Ming Luo ${ }^{3}$ \\ ${ }^{1}$ Management School, Wuhan University of Science and Technology, Wuhan, Hubei, 430081, China \\ ${ }^{2}$ Center for Industrial Policy and Management Research, Wuhan, Hubei, 430081, China \\ ${ }^{3}$ Economics and Management School, Wuhan University, Wuhan, Hubei, 430072, China \\ ajhz75@126.com
}

Keywords: Urbanization, Carbon Emissions, Energy Intensity

\begin{abstract}
This paper researches the influence factors of carbon emissions from the perspective of the China's urbanization. Firstly, based on the STIRPAT model, the paper builds a relational model of carbon emissions and urbanization. And then it uses the China's annual time series of urbanization, per capita GDP, energy intensity and carbon emissions from 1990 to 2011, to study the long-term equilibrium relationship between China's carbon emissions and urbanization level by Cointegration test and Granger-causality test. Finally, according to the analysis results, this paper gives some conclusions and policy advices.
\end{abstract}

\section{Introduction}

Along with China's rapid economic growth and urbanization is the rapid increase of carbon emissions. Especially as China's urbanization speeding up, more and more rural populations migrate to cities. Rural land convers to urban land and the carbon balance of payments is out of balance. China's urbanization will bring more carbon emissions of industries and service industry and bring more energy consumption. Meanwhile urban expansion would destroy some areas of farmland, indirectly reduce the nature's absorption of carbon dioxide and bring some environmental problem [1].

Due to the increasing growth of carbon emissions, how to balance promoting urban development and protecting the environment is a very important concern for governments departments. This paper researches the influence factors of carbon emissions from the perspective of the China's urbanization. Firstly, based on the STIRPAT model, the paper builds a relational model of carbon emissions and urbanization. And then it uses the China's annual time series of urbanization, per capita GDP, energy intensity and carbon emissions from 1990 to 2011, to study the long-term equilibrium relationship between China's carbon emissions and urbanization level by Cointegration test and Granger-causality test. Finally, according to the analysis results, this paper gives some conclusions and policy advices.

\section{Theory Model}

This paper's theory model is based on the STIRPAT model[2,3], the form of the model is as follows:

$$
I=P^{a} A^{\beta} T^{\theta}
$$

In Equation 1, I is pollution levels, namely carbon level $\mathrm{C}$; $\mathrm{P}$ refers to the population, the total population variables is expressed by the urbanization level "urb"; A refers to the level of economic development, which is expressed by per capita GDP "y"; T refers to the technical level, which is represented by energy intensity "ei"[2,3].

To test the relationship between urbanization and China's carbon emissions, this paper takes the logarithm on both sides of Equation 1, and then get the Equation 2 as follows:

$$
\ln C_{t}=\gamma+\alpha \ln y_{t}+\beta \operatorname{lnurb} b_{t}+\theta i n e i_{t}+\varepsilon_{t}
$$


In Equation 2, $I_{t}$ indicates the level of carbon emissions of the phase $t, P_{t}$ refers to the proportion of urban population, $A_{t}$ means per capita GDP, $T_{t}$ is expressed in energy intensity, $t$ refers to the year, $\varepsilon_{\mathrm{t}}$ means the random error[2,3].

\section{Model Variables}

The model variables in this research including: Urbanization rate, Carbon emissions, Per capita GDP, Energy intensity.

(1) Urbanization rate. The paper use the proportion of urban population to measure the level of urbanization.

(2) Carbon emissions, which is expressed by "C". Its calculated formula is as follows[4]:

$$
\begin{aligned}
& C=\Sigma_{t} m_{t} * \delta_{t} \\
& m_{t}=F_{t} * E
\end{aligned}
$$

In Equation 3 and 4, $\mathrm{m}_{1}$ stands for $\mathrm{i}$ kind of energy consumption, $\mathrm{E}$ stands for the total energy consumption, $F_{1}$ stands for the ith kind of energy consumption accounts for the proportion of total consumption, $\delta_{1}$ stands for coefficient of carbon emissions of ith kind of energy[4].

(3)Per capita GDP, which is expressed by "y".

(4)Energy intensity, the ratio of the total energy consumption and GDP, which is expressed by "ei".

The research's data are from China statistical yearbook, China regional statistical yearbook, China energy statistical yearbook from 1990 to 2011.

\section{Empirical Analysis}

The paper mainly uses Cointegration test and Granger-causality test to do the empirical analysis.

\section{The stationarity test of series}

For $\operatorname{lnC}$, lny, lnurb and lnei, the research does the Stationarity test of series and their difference series firstly. The results of test are shown in Table 1.

Table 1 Stationarity test of series

\begin{tabular}{ccccccc}
\hline & $\begin{array}{c}\text { ADF } \\
\text { value }\end{array}$ & $\begin{array}{c}\mathrm{P} \\
\text { value }\end{array}$ & $\begin{array}{c}1 \% \text { critial } \\
\text { value }\end{array}$ & $\begin{array}{c}5 \% \text { critial } \\
\text { value }\end{array}$ & $\begin{array}{c}10 \% \text { critical } \\
\text { value }\end{array}$ & Stationary or not \\
\hline $\operatorname{lnC}$ & 0.566520 & 0.9845 & -3.831511 & -3.029970 & -2.655194 & nonstationary \\
lny & 0.649999 & 0.9867 & -3.886751 & -3.052169 & -2.666593 & nonstationary \\
lnurb & -0.702377 & 0.8243 & -3.808546 & -3.020686 & -2.650413 & nonstationary \\
lnei & -2.022693 & 0.2755 & -3.808546 & -3.020686 & -2.650413 & nonstationary \\
$\Delta \operatorname{lnC}$ & -1.797062 & 0.3710 & -3.808546 & -3.020686 & -2.650413 & nonstationary \\
$\Delta \operatorname{lny}$ & -0.595392 & 0.4467 & -2.685718 & -1.959071 & -1.607456 & nonstationary \\
$\Delta \ln u r$ & -2.071645 & 0.2569 & -3.808546 & -3.020686 & -2.650413 & nonstationary \\
b & & & & & & \\
$\Delta \ln$ i & -1.773238 & 0.3819 & -3.808546 & -3.020686 & -2.650413 & nonstationary \\
\hline
\end{tabular}




\begin{tabular}{lllllll}
\hline$\Delta^{2} \ln C$ & -3.401248 & 0.0241 & -3.831511 & -3.029970 & -2.655194 & stationary \\
$\Delta^{2} \ln y$ & -3.222387 & 0.0388 & -3.959148 & -3.081002 & -2.681330 & stationary \\
$\Delta^{2} \ln u r$ & -4.562240 & 0.0022 & -3.831511 & -3.029970 & -2.655194 & stationary \\
$\Delta^{2} \ln e i$ & -4.437367 & 0.0028 & -3.831511 & -3.029970 & -2.655194 & stationary \\
\hline
\end{tabular}

\section{Cointegration test}

First, the research uses OLS method to do the parameter estimation, and gets the result as follows:

$$
\begin{aligned}
& \ln C_{t}=-0.9709+1.0298 \operatorname{lny}_{t}+0.1176 \operatorname{lnurb} b_{t}+1.0293 \operatorname{lnet}_{t} \\
& t=\left(\begin{array}{llll}
-5.8850) & (50.6052) & (2.59438) & (48.4437)
\end{array}\right. \\
& R^{2}=0.9995 \quad F=12382.45 \quad D . W=0.9101
\end{aligned}
$$

Then based on the residual sequence, the research uses the ADF test to infer the stationarity of random error term, the test result is shown in Table 2.

Table 2 Cointegration test

\begin{tabular}{lccc}
\hline \hline & t-Statistic & Prob. $^{*}$ \\
\hline \hline Augmented Dickey-Fuller test statistic & -3.007320 & 0.0047 \\
\hline Test critical values: & $1 \%$ level & -2.685718 & \\
& $5 \%$ level & -1.959071 & \\
& $10 \%$ level & -1.607456 & \\
\hline \hline
\end{tabular}

The test result $\mathrm{t}=-3.0073$ indicates that, the total carbon emissions has a long-term equilibrium relationship with per capita GDP, urbanization rate, energy intensity.

\section{Eliminate the serial correlation}

According to the result of OLS regression, explanatory variables are passed the T test, but the DW value is very small. It indicates that the models are related. Using Cochrane-Orcutt iterative method to modify the original model, the results could be obtained as follows.

$$
\begin{aligned}
& \ln C_{t}=-1.3082+1.0366 \operatorname{lny}_{t}+0.1615 \text { lnurb }_{t}+1.0728 \text { lne }_{t}+0.5776 \mathrm{AR} \\
& t=\left(\begin{array}{lllll}
-4.294) & (34.9825) & (2.4535) & (25.9960) & (3.1457)
\end{array}\right. \\
& R^{2}=0.9997 \quad F=13808.58 \quad D . W=1.997
\end{aligned}
$$

$\mathrm{DW}=1.997$ shows that the autocorrelation of equation has been eliminated. The results indicate that GDP per capita, urbanization rate, energy intensity and carbon emissions are positively related. $1 \%$ growth in urbanization rate, will cause $0.1615 \%$ growth in carbon emissions, $1 \%$ growth in GDP per capita and $1.0366 \%$ growth in total carbon emissions respectively. $1 \%$ growth in energy intensity, will cause $1.0728 \%$ growth in total carbon emissions.

\section{Granger-causality test}

The paper uses the Granger-causality test to test the causal relationship between total carbon emissions and urbanization rate, the test result is shown in Table 3.

The results shows that, the hypothesis "lnU is not lnC's Granger reason" could not be rejected in the F test, which means urbanization is the cause of the sustainable growth of carbon emissions; the 
hypothesis "InC is not lnU's Granger reason" could be rejected in the F test, which means carbon emissions is not a motivating factor of urbanization.

Table 3 Granger-causality test

\begin{tabular}{lccc}
\hline \hline Null Hypothesis: & Obs & F-Statistic & Prob. \\
\hline \hline LNURB does not Granger Cause LNC & 20 & 7.76766 & 0.0048 \\
LNC does not Granger Cause LNURB & & 0.18145 & 0.8359 \\
\hline \hline
\end{tabular}

\section{Conclusions}

This paper studies the long-term equilibrium relationship between China's carbon emissions and urbanization level by Cointegration test and Granger-causality test with the data from 1990 to 2011. Through the above analysis, this research formed the following conclusions:

Empirical analysis indicates that GDP per capita, urbanization rate, energy intensity and carbon emissions are positively related. $1 \%$ growth in urbanization rate, will cause $0.1615 \%$ growth in carbon emissions, $1 \%$ growth in GDP per capita and $1.0366 \%$ growth in total carbon emissions respectively. $1 \%$ growth in energy intensity will cause $1.0728 \%$ growth in total carbon emissions. It also shows that total carbon emission is effected not only by the current period elements but also by the earlier state ones. And the current period carbon emissions may be influenced by the use habit of energy such as the current stage wealth level, urbanization, energy efficiency, etc. In the long term, the great influence of the urbanization level in China on the carbon emissions level after the reform and opening-up proves that urbanization is one of the important elements that cause the increase of the carbon emissions in China. Granger test indicates that urbanization is the cause of the sustainable growth of carbon emissions which is not a motivating factor of urbanization.

Low carbon-emissions will not necessary hinder the economic development. The governments departments can, through shaping healthy and civilized consumer culture and so on, achieve the sustainable development ultimately, and lessen the effect of the urbanization on environment.

\section{Acknowledgements}

This work was financially supported by MOE (Ministry of Education in China) Project of Humanities and Social Science (No.15YJCZH221), Foundation of Center for Industrial Policy and Management Research (No.CY20150211), and Youth Project of Wuhan University of Science and Technology (No.2015XZ021).

\section{References}

[1]Ming Zhang, Hailin $\mathrm{Mu}$, Yadong Ning, Yongchen Song: Ecological Economics,2009, 68(7):2122-2128.

[2] DietzT, RosaEA: Human Ecology Review,1994(1):277-300.

[3] DietzT, RosaEA: Proceedings of the National Academy of Sciences,1997,94(1):175-179.

[4]GUAN Hailing, CHEN Jiancheng, CAO Wen: China Population, Resource and Environment, 2013,23(4):111-116(in Chinese). 